\title{
A COMPREENSÃO DA CULTURA PELO ATO RESPONSÁVEL E PELA ALTERIDADE DA PALAVRA DIALÓGICA NOS ESTUDOS BAKHTINIANOS
}

\author{
HÉLIO MÁRCIO PAJEÚ* \\ VALDEMIR MIOTELLO
}

\begin{abstract}
RESUMO: A compreensão da cultura como orbe simbólico do homem em interação com seu outro faz com que os contextos cotidianos tomem lugar nas reflexões sobre essa temática, promovendo um novo conjunto teórico para se compreender as ações e interações humanas nos seus horizontes sociais. É por essas veredas que Bakhtin e o Círculo, em seu plano epistemológico, compreendem a cultura sob um caráter sui generis, discutindo-a sob a perspectiva da alteridade e das relações dialógicas como o espaço de vivência do ato ético na esfera cotidiana e da consolidação da estética, bem como a instância dos entraves sociais, posto que para ele a cisão entre a vida e a cultura torna esses dois domínios objetificados. Destarte, este trabalho configura uma discussão teórica que pretende refletir a concepção de cultura a partir dos postulados bakhtinianos na sua relação com a vida, vista sob o princípio da alteridade, da responsabilidade e da palavra outra em sua forma mais dialógica.

Palavras-chave: cultura; alteridade; ato responsável; dialogia; encontro de palavras.
\end{abstract}

\begin{abstract}
The understanding of culture as symbolic of man orb interacting with his other makes everyday contexts take place in the reflections on this theme, promoting a new theoretical set to understand the man's actions and interactions in their social horizon. For these paths that Bakhtin and the Circle in its epistemological level, understand the culture under a sui generis character, discussing it from the perspective of otherness and the dialogical relations as the ethical act of living space in everyday sphere and consolidation aesthetics, and the resort of social barriers, since for that he split between life and culture makes these two areas objectified. Thus, this work sets a theoretical discussion that aims to reflect the concept of culture from Bakhtin postulates in its relationship with life, seen from the principle of otherness, responsibility and another word in its dialogical form.
\end{abstract}

Keywords: culture; otherness; responsible act; dialogy; meeting of words.

\section{INTRODUÇÃO}

É o modo de agir do homem no mundo ético, o seu existir enquanto ser, na sua vivência cotidiana que vai despertar o interesse de Mikhail Bakhtin e do Círculo para o estudo da cultura. Todavia, isso se dá não como algo objetivado, uma vez que para esse grupo de pensadores a separação teorética entre vida e cultura, tornada domínio autônomo, causa o esgotamento dos sentidos nas interações

*Universidade Federal de Pernambuco (UFPE), Recife, PE, Brasil. heliopajeu@yahoo.com.br

${ }^{* * *}$ Universidade Federal de São Carlos (UFSCar), São Carlos, SP, Brasil. miotello@terra.com.br 
humanas, a deterioração da própria ação que, "isolada dos significados da cultura, empobrecida de seus ideais, decai para o patamar de motivações biológicas e econômicas elementares; portanto, parece que fora da cultura objetiva não há nada mais que a individualidade biológica nua" (PONZIO, 2010, p. 25).

Em toda obra produzida por esses pensadores, há compreensões ativas dos processos de constituição dos eventos que formam a arquitetônica da cultura na sua relação direta e imanente da vida. Portanto, eles não buscarão compreender as bases biológicas que distinguem o homem do animal, numa tentativa de apartar de modo esquemático o orbe da cultura das interações da vida. Pelo contrário, para a concepção bakhtiniana, o que se encontra como ponto central são as relações de alteridade, ideologia e singularidade do ato responsável, que possibilitam a concretização dessas esferas. Na realidade, toda unidade transcendental da cultura objetiva é obscura e elementar, uma vez que esta é totalmente "separada pelo centro único e singular da consciência responsável; uma total separação é na realidade impossível e, enquanto realmente pensamos aquela unidade, ela brilha com a luz refletida da nossa responsabilidade" (BAKHTIN, 2010, p. 82).

A compreensão da cultura como esfera simbólica do homem em interação com seu outro faz com que os contextos cotidianos tomem lugar nas reflexões sobre essa temática, promovendo um novo conjunto teórico para se compreender as ações e interações do humanas nos seus horizontes sociais. $\mathrm{O}$ entendimento das relações humanas só pode ser concreto a partir da lógica da realidade que se faz presente no cotidiano dos sujeitos, da realidade do povo, que não pode ser constituída a partir de uma superfície ideal. No entanto, seu valor deve fornecer os embasamentos que amparam a desmedida composição econômica, que nada mais é do que o próprio mundo material, o mundo real e mundo cultural (BAKHTIN; VOLOCHÍNOV, 2009). Para tanto, os eventos que arquitetam a relação cultura e vida são ponderados por essa filosofia dialógica na sua relação de existência como evento único, irrepetível e singular composta por atos responsáveis.

Destarte, este trabalho se configura como uma discussão teórica que pretende refletir a concepção de cultura e sua relação com a vida apregoada nos Estudos Bakhtinianos, vista a partir do princípio da alteridade, da responsabilidade e da palavra outra em sua forma mais dialógica.

\section{VIDA E ARTE, ÉTICA E ESTÉtiCA NA CONSTITUIÇÃo DA CULTURA}

O centro de valor da alteridade que constitui a relação eu-outro é o que permite aos acontecimentos que circunscrevem a cultura se concretizarem com vivacidade nas relações sociais, posto que, para Bakhtin, a cisão entre a vida e a cultura torna esses dois domínios objetificados. Como resultado desse processo temos dois mundos que se confrontam, dois mundos categoricamente fechados: o mundo da cultura e o mundo da vida - o mundo no qual se objetiva o ato da atividade de cada sujeito e o mundo em que tal ato verdadeiramente, irrepetivelmente, incide e tem lugar como representação. 
Isso faz despontar direções contrapostas: uma unidade objetiva de um domínio da cultura e a singularidade irrepetível da vida vivenciada na sua concretude. Entretanto, isso não ocorre sob um plano unitário e único. Exclusivamente o evento singular do existir pode compor essa unidade única. "O ato deve descobrir um único plano unitário para refletir-se em ambas as direções, somente assim se pode superar a perniciosa separação e a mútua impenetrabilidade entre cultura e vida" (BAKHTIN, 2010, p. 43).

De modo objetivado, esses dois mundos não se comunicam entre si e não existe uma abertura que convenha para abarcar e invadir o mundo válido da cultura teorizada no existir-evento singular da vida (BAKHTIN, 2010). Bakhtin proporciona um exame crítico à dissensão da eventicidade do ser em duas perspectivas: o experimento vivenciado, os atos concretizados na esfera da vida, isto é, o lugar da efetivação da atividade ética, dos atos que são impérvios em sua singularidade e a esfera da cultura, como mundo da significação, dos atos valorados, da representação ajustada por ele como um fato objetivo, como unidade objetiva de atos representados em enunciados, por meio da linguagem. Temos então duas esferas que se misturam para constituir os sentidos que o pensador chama de ética e estética.

Aconcepção de ética fundamentada pelos postulados dos estudos bakhtinianos, portanto, faz referência à ação da existência e constituição de uma vida singular, do jogo interativo do homem, do ato de ousadia, de comprometimento, de assinatura responsável que integra o ponto de vista de cada sujeito no contexto da vivência e da interação social. Ético, nessa acepção, refere-se à ação, ao agir no mundo, à precisão de ocupação do lugar único no mundo; se trata de um conjunto de comprometimentos e deveres dos sujeitos em relação com seus outros.

A estética por sua vez, aparece como os modos de acabamento do agir dos sujeitos. O objeto estético encarna uma valoração, uma reflexão elaborada, portadora de acabamento - e não essencialmente acabada - acerca da ação ética desempenhada pelo sujeito a partir da linguagem. A concepção estética resulta de um processo que busca representar o mundo sob um ponto de vista exotópico do sujeito, de um posicionamento de fronteira de onde o homem enxerga o mundo com adequado distanciamento; para transfigurá-lo na edificação da sua palavra estética e que carrega também os aspectos sociais e históricos. É propriamente o lugar da representação, do simulacro. Nessa mesma linha, Ariano Suassuna (1979, p. 70), ao discutir o campo estético na arte, assegura que "a satisfação determinada pelo juízo estético se apoia no livre jogo da imaginação, é uma espécie de harmonização das faculdades causada pela sensação de prazer."

Bakhtin, na sua Filosofia do ato responsável, reitera que todos os eventos e objetos do mundo material só adquirem sentidos ao adentrarem no universo social do homem, ao se constituírem a partir de centros de valores únicos, ao se humanizarem por intermédio da linguagem. É esse processo de constituição dos sentidos que configura as esferas da vida e, nesse sentido, a atividade estética se abre como a possibilidade de um evento de representação do existir éticosingular. Ela só principia sua existência quando o sujeito toma uma posição fora do evento do qual fala, do evento do qual compreende, do evento do qual vive, 
quando esse se conforma pela palavra como representação. A atividade estética se inicia dessa condição de extralocalização e estranhamento, da impossibilidade de recomposição do eu e, justamente por isso, é capaz de mostrar, mais do que qualquer outro lugar do discurso, o propriamente humano e as suas relações essenciais" (PETRILLI, 2013, p. 83).

A compreensão e consolidação da atividade estética requerem um afastamento do ato ético que só é permitido pela exotopia, pelo encontro com a alteridade, pela transgressão da própria identidade do eu. A cultura é, portanto, o lugar de junção desses dois mundos, da vida e da arte, da ética e da estética e "se eu me afasto desse lugar único, ocorre uma cisão entre o mundo infinito possível do conhecimento e o pequeno mundo de valores por mim reconhecidos" (BAKHTIN, 2010, p. 110).

\section{O ATO RESPONSÁVEL COMO FUNDAMENTO DA AÇÃO ÉTICA NO UNIVERSO DA CULTURA}

Para Bakhtin (2010), somente o ato responsável extrapola toda proposição, posto que ele é - de um modo infalível, irremediável e irrevogável - a concretização de uma deliberação, de uma tomada de decisão. $\mathrm{O}$ ato é a consequência derradeira, uma exímia conclusão determinante que dirige, correlaciona e delibera em uma conjuntura única e singular o sentido e o fato, o universal e o individual, o real e o ideal, porquanto tudo entra no arranjo de sua motivação responsável; $\mathrm{o}$ ato funda $\mathrm{o}$ germinar de mera probabilidade na singularidade de escolha de uma vez por todas.

É pela axiologia, pela tomada de posição frente ao mundo que o ato permite aos sujeitos tornar a arquitetônica da cultura uma unidade não abstratamente metódica, mas valorativa, a partir da posição única que cada um ocupa, de maneira insubstituível no mundo, enquanto núcleo participativo e não indiferente nos seus arrolamentos com o outro.

O ato responsável é o que arquiteta aquilo de mais absoluto na constituição da identidade do eu, pois ele garante a unicidade, a singularidade dos sujeitos que participam de um diálogo com outros sujeitos únicos, pelo qual exprimem em suas enunciações os feitios da alteridade e da palavra alheia. Essa unicidade não se refere a um sujeito "associal, reduzido a uma entidade puramente biológica, confinado na esfera das necessidades fisiológicas" (PONZIO, 2010, p. 25), mas a um sujeito ativo, sem álibis, cujo diálogo e as interações sócio ideológicas com seus outros funcionam como elementos que esboçam o encontro de palavras materializados na cultura, por meio dos mais variados gêneros do discurso que caracterizam as interações humanas.

Eles atestam que é a diferença o único meio da constituição do sentido do homem, pois o mundo humano nasce da diferença, do embate, da distinção e é "a semelhança da diferença que constitui a base da diferença, pois toda coisa que difere de outra coisa tem alguma semelhança com ela. Sem semelhança, os diferentes sujeitos seriam simplesmente incompatíveis, em vez de diferentes [...]. Pode-se mesmo dizer que o sentido nasce da diferença, só na diferença podemos encontrar sentido". (SOBRAL, 2009, p 58). 
Assim, a cultura é o lugar da diferença, da identidade que se constrói pela alteridade e, nessa direção, a igualdade procustiana é deletéria. Pela diferença o sujeito reconhece o outro, percebe aquilo que ele vivencia; apreende, sobretudo, o horizonte social que evidencia as lacunas que só são visíveis do seu lugar, as fissuras que só podem ser preenchidas pela alteridade. É a cultura na interação com a vida, com todos os seus fenômenos associados, que vai permitir tal preenchimento pela linguagem.

Nessa direção, a cultura é a lente pela qual os sujeitos valoram os seus atos e os atos alheios nas esferas ética e estética, e aí a compreensão da cultura por uma vertente enrijecida da identidade só pode ter como implicação a reação de estranheza em presença do diferente,

"a propensão em considerar o seu modo de vida como o mais correto e o mais natural. Tal tendência, denominada etnocentrismo, é responsável em seus casos extremos pela ocorrência de numerosos conflitos sociais. Comportamentos etnocêntricos resultam também em apreciações negativas dos padrões culturais de povos diferentes" (LARAIA, p. 2001, p. 72-4).

Compreender a cultura por uma perspectiva da alteridade, constituída de atos responsáveis, permite distanciar-se de um etnocentrismo amargo, uma vez que a alteridade é exatamente o elemento que abre o sujeito, que o torna inacabado, que o faz recolher a diferença como fundamento da sua incompletude, por essa ser ubíqua. Por isso mesmo,

não se deve, porém, imaginar o domínio da cultura como uma entidade espacial qualquer, ele está inteiramente situado sobre fronteiras, fronteiras que passam por todo lugar, através de cada momento seu, e a unidade sistemática da cultura se estende aos átomos da vida cultural, como o sol se reflete em cada gota. Todo ato cultural vive por essência sobre fronteiras: nisso está sua seriedade e importância; abstraído da fronteira, ele perde terreno, torna-se vazio, pretensioso, degenera e morre (BAKHTIN, 2010a, p. 29).

Destarte, essa compreensão de cultura engloba os eventos e atos responsáveis que não podem ser vistos fora da interação social dos sujeitos, que não podem ser compreendidos de modo objetificado, de modo teorético e com vida própria em relação aos seus sujeitos, "uma vez que somente como grupo social, de uma classe social é que o indivíduo ascende a uma realidade histórica e a uma produtividade cultural" (GEGE, 2009, p. 26).

A cultura nasce na vivacidade do cotidiano, nas entranhas dos embates entre a infra e a superestrutura, na tensão entre o hegemônico e o marginalizado e se embrenha por todas as dimensões da vida humana, pois ela está presente nas vozes e imagens que nos interpelam nas interações cotidianas. Ela se erige como um artifício acionador do modo pelo qual os sujeitos podem ser constituídos e reconhecidos como únicos. Para Bakhtin, tal reconhecimento se dá somente pelo ato responsável que singulariza os sujeitos nas suas interações e garante a constituição das identidades múltiplas pela entrada da alteridade no jogo ético das relações subjetivas, o que torna a concepção de sujeito integral, fechado e acabado dentro de um mundo igualmente teorizado, miserável. Nessa direção, Geraldi, (2014, p. 7) mediado pela compressão dos pensamentos bakhtinianos, 
assevera que "o mundo não nos é dado, mas construído; para edificar o mundo, ninguém parte do nada! Sobre uma natureza encontrada, dada, operamos todos nós e jamais sozinhos: é preciso pensar que sobre ela atuam outros seres com quem partilhamos a vida. Mas entre esses, somente nós "elaboramos" o mundo, pois lhe damos sentidos, jamais dados, jamais acabados, jamais prontos, jamais definidos". E o mundo elaborado, construído, arquitetado pelas mais variadas relações sociais entre o eu e o outro é o que constitui as mais variadas esferas da cultura.

\section{A CULTURA PELO OLHAR BAKHTINIANO DA ALTERIDADE}

É justamente a alteridade que abafa o monologismo e possibilita aos sujeitos se orquestrarem, a partir de uma polifonia social, em suas tomadas de decisão no mundo ético e na elaboração dos sentidos do mundo no qual interagem. É a ação de reconhecer-se como sujeito constituinte de ato responsável que põe a alteridade como elemento que destrói o mundo teórico; elemento que impossibilita a relação espontânea entre vida e cultura no mundo concreto do existir, uma vez que nesse mundo "não é possível viver, agir responsavelmente, nele não sou necessário, nele por princípio não tenho lugar” (BAKHTIN, 2010, p. 52). Logo, compreender a arquitetônica que une cultura e vida requer partir de uma filosofia que se propõe a instaurar "uma relação que permite a manutenção da alteridade do centro de valor de tal arquitetônica, que é considerado de um ponto de vista transgrediente, por sua vez único e outro" (PONZIO, 2010, p. 31), isto é, uma filosofia da vida.

Aalteridade é o recinto pelo qual podemos nos identificar, aprender a coexistir; vivenciar o diferente e fazer ressurgir o sujeito - "não como representação de um Deus fundador com o qual cada um tem endividamentos de concretizar na vida sua perfeição, todavia, um sujeito frágil, exorbitantemente humano, cuja identidade, estabilidade instável, se define pelos gestos de responsabilidade de ordenar a experiência do nosso fazer e do nosso padecer" (GERALDI, 2010, p. 120).

É esse lugar de identificação fora de um subjetivismo idealista e de um objetivismo abstrato que configura a cultura como espaço de reconhecimento do outro, no qual os sujeitos consolidam atos responsáveis com significados para outros sujeitos em situações determinadas, compostas por sujeitos outros capazes de ação e reação, por instituições e coisas, e, sobretudo, compostos por respostas que ecoam na cadeia da comunicação verbal e que renovam os embates sociais que, por sua vez, interferem e escrevem a história como uma ação ininterrupta de modificação e subversão da condição humana, como a cultura.

A cultura, logo, se arma como o lugar de concepção do eu na interação com o outro, em que o

\footnotetext{
"eu vai se impondo, não mais como construtor, mas como constructo. Pensar o eu como constructo não joga fora a questão da identidade, mas ela não é mais vista como ponto de partida. O ponto de partida é o construtor, e esse é o outro. Um eu que é pensado é um eu que tem sua existência concedida pelo outro. Logo a questão que se impõe não é mais a questão da identidade, mas é a questão da alteridade. Eu sou pensado, logo eu existo, e penso" (MIOTELLO; MOURA, 2012, p. 11).
} 
O lugar de pensar, de ser pensado e de interação entre o eu e o outro é a cultura, é a vida. Assim, a cultura da alteridade compreendida a partir da vida, como pensa Bakhtin, funciona como um meio para abrir nossos olhos para compreender o que somos e o que seremos, aquilo que faz parte de nós e que nos constitui como seres únicos no existir; é algo que se concretiza, na medida em que consolidamos atos responsáveis, em que avançamos para compreender o outro, o que é alheio, o que nos falta, o que constitui a palavra outra.

A vida, diz Bakhtin (2010, p. 142), "conhece dois centros de valores, diferentes por princípio, mas correlatos entre si: o eu e o outro, e em torno desses centros se distribuem e se dispõem todos os momentos concretos do existir". Nesse sentido, a cultura se firma como cultivo, não somente da terra, nem do espírito, como prescreve sua etimologia, mas como atmosfera úbere para se cultivar a relação com o outro, na sua diferença, unicidade e singularidade.

É por essas veredas que Bakhtin e o Círculo, em seu plano epistemológico, compreendem a cultura sob um caráter sui generis, como o espaço de vivência do ato ético na esfera cotidiana e da consolidação da estética, bem como a estância do suceder e do rejuvenescer dos entraves sociais. Por esse modo, ela é um elemento que caracteriza a linguagem - o aspecto sígnico do homem - como a arena em que se dão as pelejas discursivas e sociais, uma vez que o signo e a situação social estão indissoluvelmente a ela vinculados.

Ela assume o papel de um aparato simbólico desafiador e crítico às interações de dominação entre os sujeitos, por isso não é por si mesma, não se conforma autônoma e objetiva na sua imanência. Entretanto, se trata de um procedimento que se dá pela dependência de alteridades distintas, em que o outro que se funde socialmente no processo interativo de constituição da subjetividade carece em alto grau de um outro oposto, diferente, que o singularize na sua identidade, na sua relação com o social. Nesse sentido, Geraldi (2010, p. 113) compreende que "as identidades socialmente constituídas nas relações com o outro - outros fazem múltiplas as identidades de cada um" e isto torna o fenômeno cultural rico, enérgico, como o lugar de instituição da diferença como princípio constituinte das subjetividades.

O processo de constituição do sujeito, o seu inacabamento que é evidenciado na íris do outro, é discutido intensamente por Bakhtin ao longo de toda sua obra e se fundamenta como um dos princípios que direcionam a sua filosofia ética, pela qual ele nos faz compreender que o ato responsável requer a alteridade, pela qual nos permite também compreender a cultura que envolve os grupos socialmente organizados no seio da vida. Nessa perspectiva, Geraldi (2010, p. 85) identifica o ato responsável bakhtiniano como uma resposta que arranja um diálogo sucessivo, pelo qual buscamos no prosseguimento da história, nos eventos, nas singularidades, nas unicidades dos atos do nosso caminhar a realização das "respostas responsáveis, como um modo de reencontrar os deslocamentos imperceptíveis na construção continuada dos valores, dos sentidos que regem, mas que se fazem e se desfazem na existência".

Tais sentidos, nas interações humanas, circunscrevem os modos de constituição da identidade dos sujeitos que, na perspectiva dialógica de Bakhtin, 
só pode ser admitida a partir do outro, posto que ele faça parte do existir enquanto evento da vida apesar de mim; logo, a responsabilidade é atributo constituinte da alteridade, uma vez que nela a questão do sentido do homem é tratada sob a categoria do outro e não do eu.

Do ponto de vista da identidade, mesmo de um grupo socialmente organizado, "não se pode descobrir o sentido do homem, apenas falsificá-lo. De fato, numa perspectiva como essa o sentido do homem coincide com interesses particulares e limitados, apesar de serem comuns. Para se opor a tal perspectiva é necessário o ponto de vista da alteridade". (PONZIO, 2008, p. 26). É somente pelo encontro de palavras da alteridade que a cultura se configura como a esfera simbólica dos atos humanos que, imediatamente, tem na sua imanência a dialogicidade que carrega em si ressonâncias e memórias de atos precedentes.

É nas condições concretas da interação entre sujeitos que podemos desvendar as palavras alheias, apagadas, disformes e com escalas distintas de absorção do outro, do diferente, de alteridades e essas alteridades "não são sujeitos ou individualidades soltas no mundo, mas individualidades e subjetividades que se constroem no processo mesmo de uso de linguagem, no contexto de uma organização social e seus modos de relações, também essas historicamente mutáveis" (GERALDI, 2010, p. 78).

Dentro dessa concepção semântica, a cultura se configura como um conjunto de eventos únicos e concretos que pertencem ao domínio cotidiano, isto é, pertencente à história e está, espontaneamente, acoplada aos seus eventos sociais. Ao ponderar "todas as significações culturais (cognitivas, éticas e estéticas), chega-se bem facilmente à conclusão de que não existe absolutamente nada na cultura além da palavra, que toda a cultura não é nada mais que um fenômeno na língua, que o sábio e o poeta em igual medida se relacionam somente com a palavra” (BAKTHIN, 2010a, p. 45, grifo nosso).

\section{A PALAVRA IDEOLÓGICA COMO LUGAR DE ARQUITETURA DA CULTURA DIALÓGICA}

E por quê pela palavra? Porque a "representação do mundo é melhor expressa por palavras, pois que não precisa de outro meio para ser produzida a não ser o próprio ser humano em presença de outro ser humano" (MIOTELLO, 2010, p. 170). Os acontecimentos éticos só podem ser compreendidos a partir da ordem estética, que organiza e dá acabamento provisório pelo emprego e uso da linguagem. Pela palavra "enquanto signo ideológico, signo dialógico, realizado concretamente na vida da linguagem, da língua, do discurso em enunciados concretos. O limite da ciência é a palavra" (SOUZA, 2002, p. 140).

Não existem palavras neutras, indiferentes, não pode haver, na realidade, senão palavras artificialmente neutralizadas. O que caracteriza os fenômenos mais antigos da linguagem é, aparentemente, a fusão do elogio e da injúria, a dupla tonalidade da palavra. [...] A palavra de dupla tonalidade permitiu ao povo que ria, e que não tinha o menor interesse em que se estabilizassem o regime existente e o quadro do mundo dominante (impostos pela verdade 
oficial), captar o todo do mundo em devir, a alegre relatividade de todas essas verdades limitadas de classe, o estado de não acabamento constante do mundo, a fusão permanente da mentira e da verdade, do mal e do bem, das trevas e da claridade, da maldade e da gentileza, da morte e da vida (BAKHTIN, 2008, p. 380).

O que interessa a Bakhtin, em toda a sua filosofia, ao procurar compreender a cultura pela palavra dialógica, alargada, é, antes de tudo, compreender como a vida integra a arte e vice-versa, é auscultar as vozes que dão corpo aos encontros de palavras de alteridade, posto que ela "pertença de alguma forma ao próprio tempo, que dá morte e a vida no mesmo ato; por isso a palavra tem duplo sentido e é ambivalente (BAKHTIN, 2008,p. 250). A língua passa a integrar a vida através de enunciados concretos (que a realizam); é igualmente através de enunciados concretos que a vida entra na língua (BAKHTIN, 2003). Portanto, estudar a cultura pela palavra que a dá feitio é compreendê-la como uma "unidade aberta, em evolução, não determinada nem predeterminada, capaz de se perder ou de se renovar, transcendendo a si mesma (ultrapassando seus próprios limites)" (BAKHTIN, 2003, p. 374).

Valentin Volochínov (2014, p. 193), em seu ensaio A palavra e sua função social, responde tal pergunta de modo categórico, ao afirmar que a palavra na acepção do Círculo de Bakhtin se faz de signos materiais que suscitam respostas avaliativas e, nesse sentido, ela "por sua própria natureza intrínseca, é desde o início um fenômeno puramente ideológico. Toda realidade objetiva da palavra consiste exclusivamente na sua destinação de ser um signo. Na palavra não existe nada que seja indiferente a essa destinação e que não tenha sido por ela gerado". Isto é, a palavra carrega consigo a ideologia da realidade material, do mundo dos produtos culturais que tomam valor a partir da interação dos sujeitos.

Ao olhar para a esfera da cultura, Ortiz (1985, p. 136) compreende a ideologia como "uma concepção de mundo orgânica da sociedade como um todo (ou visando à totalidade) e como tal age como elemento de cimentação da diferenciação social". Thompson (1995), ao discutir a multiplicidade de sentidos para o termo ideologia e as suas relações com a cultura moderna, afirma que ideologia é o pensamento do outro. Na tentativa de reformular tal conceito e desprendê-lo dos sentidos tradicionais e negativos que o mesmo acumulou ao longo da história, ele o retoma considerando-o imerso em um conjunto de questões que trazem à baila às inter-relações entre sentido e poder. Nessa esteira, o autor argumenta que "ideologia pode ser usado para se referir às maneiras como o sentido serve, em circunstâncias particulares, para estabelecer e sustentar relações de poder que são sistematicamente assimétricas" (THOMPSON, 1995, p. 173).

Ambas as concepções tratadas aqui, ao relacionarem ideologia e cultura, estabelecem pontos em comum com o que Bakhtin, anteriormente, considerou em sua obra como ideológico ao olhar a relação entre cultura, linguagem e vida. Ponzio (2013, p. 179) considera que ideologia para Bakhtin

indica tanto as diferentes formas da cultura, os sistemas superestruturais como a arte, o direito, a religião, a ética, a consciência científica etc (a ideologia oficial), quanto as diferentes camadas da consciência individual, as que coincidem com a ideologia oficial e as que coincidem com 
a ideologia não oficial e as camadas do inconsciente, do discurso censurado. A ideologia é a expressão das relações materiais dos homens, onde "expressão" não significa somente interpretação ou representação, mas também organização e regulamentação dessas relações.

Seguramente, Bakhtin e Volochínov se inquietaram, com mais obstinação, pelo modo como essa regulamentação material das relações humanas e as várias vozes que as constituem se encontram na palavra, reciprocamente, como os vemos filosofarem em Marxismo e Filosofia da Linguagem (2009). Nele, ao tratar das relações entre a infraestrutura e a superestrutura, eles elaboram uma reflexão a respeito das forças dicotômicas que se digladiam e se mostram por meio dos signos e que mais tarde serão nomeadas de ideologia oficial e ideologia do cotidiano.

Volochinov (2014, p. 151) mostra que a ideologia do cotidiano se trata de "todo o conjunto de sensações cotidianas - que refletem e refratam a realidade social objetiva - e as expressões exteriores imediatamente a elas ligadas. Ela dá significado a cada ato nosso, a cada ação nossa e a cada um de nossos estados conscientes". Ela é aquela mais instável nas lutas sociais. Miotello (2010, p. 168) ajuda a compreender melhor esses pensamentos ao esclarecer que

a ideologia oficial é entendida como relativamente dominante, procurando implantar uma concepção única de produção de mundo. A ideologia do cotidiano é considerada como a que brota e é constituída nos encontros casuais e fortuitos, no lugar do nascedouro dos sistemas de referência, na proximidade social com as condições de produção e reprodução da vida.

Em cada uma dessas esferas em que as palavras são entoadas, elas se realçam, se colorem de sentidos convenientes, determinados ao ofício dos proveitos e interesses de cada grupo. Em cada domínio da comunicação discursiva encontramos "a posição do falante nesse ou naquele campo do objeto e do sentido. A escolha dos meios linguísticos e dos gêneros de discurso é determinada, antes de tudo, pelas tarefas (ideia) do sujeito do discurso (autor) centradas no objeto e no sentido" (BAKHTIN, 2003, p. 289).

A constituição dos sentidos é de fato uma batalha. De um lado, temos a ideologia oficial, como estrutura, como conteúdo, relativamente estável, do outro temos a ideologia do cotidiano, como acontecimento, relativamente instável. Ambas em interação formam o conjunto ideológico completo e único, em relação recíproca, sem perder de vista a concretude social. Nesse universo, "a palavra é a ponte, elemento de mediação, é ela que carrega de um para o outro o ponto de vista único de cada um, e que vai constituir o outro, constituindo a identidade do eu" (GEGE, 2009, p. 84).

A palavra é nessa perspectiva o limite da cultura. Entretanto, cada ato cultural usa a palavra de modo diferente. $\mathrm{O}$ conhecimento não tem o que fazer, por exemplo, com o aspecto sonoro da palavra. Embora a cultura seja um fenômeno da língua e não viva sem ela, o domínio cultural tira dela muito pouco. Nesse sentido, a poesia revela sua particularidade em relação aos outros atos culturais: somente a poesia precisa da língua por inteiro, valorizando os mínimos aspectos de sua constituição material. É como se a poesia espremesse todos os sucos da língua que aqui se supera a si mesma (MACHADO, 1990, p. 136). 
Para Bakhtin, a palavra pressiona todos os canais da vida. Ela envolve todas as significações culturais entrelaçadas por diretrizes dialógicas e ideológicas que expressam a multiplicidade das contradições sociais pela linguagem, pelos signos ideológicos que formam enunciados e integram os processos interativos dos sujeitos com outros sujeitos por meio dos seus bens culturais. Essa palavra é sempre palavra alheia, esse alheio é a alteridade e isso evidencia um nível elevado de interação subjetiva no universo da cultura. Posto que um "eu somente pode realizar-se na palavra se se apoia nos outros" (VOLOCHÍNOV, 2014, p. 80), ela exprime sempre um ponto de vista a respeito dos acontecimentos da realidade da vida e da realidade da cultura.

Esse processo torna possível refletir sobre o orbe da cultura a partir de uma compreensão dialógica dos fenômenos discursivos, processos e atos que constituem os horizontes sociais do homem e dos seus "grupos específicos que estabelecem sistemas específicos de atribuição de ordem ao mundo [...] e em cada um deles os signos se revestem de sentidos próprios, produzidos a serviço dos interesses daquele grupo" (MIOTELLO, 2004, p. 171). E nessa perspectiva de uma teoria dialógica, deve-se necessariamente reconhecer a infinitude do processo dialógico, em que todo dizer e todo dito dialogam com o passado e o futuro, e paradoxalmente, deve reconhecer a unicidade e irrepetibilidade dos enunciados produzidos em cada diálogo. É aceitar essa fórmula paradoxal: todo enunciado é único, mas nenhum isolado" (GERALDI, 2012, p. 20). É aceitar que toda palavra é singular, mas ao mesmo tempo é povoada por outras vozes da alteridade, é dialógica.

Somente a palavra pode impregnar em si a história dos valores axiológicos e volitivos "dos grupos humanos organizados; as palavras sígnicas serão as portadoras dos sonhos e das frustrações de cada grupo organizado, elas constituirão a memória do passado e a memória do futuro, o retrato mais fiel da vivência e do modo de vida de cada grupo social" (MIOTELLO, 2004, p. 70).

A palavra configura e se emboca em cada esfera singular da totalidade social, constituindo a mediação entre os sujeitos pela significação dos seus atos e se projetando como elemento central ao entendimento das relações humanas e discursivas. Isto porque a realidade que constitui o mundo ético é quem determina os elementos semióticos que compreendem os signos e esses refletem e refratam essa mesma realidade em transformação que dá feitio ao conjunto de atos que moldam o domínio da cultura.

"Todas as palavras e formas são povoadas de intenções [...] são semi-alheias, que só se tornam próprias quando o falante as povoa com sua intenção, com seu acento, quando as dominam através do discurso, as tornam familiar com a sua orientação semântica expressiva" (BAKHTIN, 2010a, p. 100). Portanto, não se trata de uma palavra neutra, mas a "palavra concebida mais amplamente, como um fenômeno da comunicação cultural, que deixa de ser uma coisa centrada em si mesma e já não pode ser compreendida independente da situação social que a tem engendrado" (VOLOCHÍNOV, 2014, p. 75). 
Ortiz, ao discutir a cultura em relação à identidade nacional, reconhece que se atentar à palavra para analisar os discursos é um meio eficaz de se abarcar a esfera cultural, posto que essa reflexão permite

compreender como determinados grupos agenciam suas ideias e procuram apreender o mundo tendo como ponto de referência os conceitos centrais que elaboraram. No entanto, é necessário perceber que todo discurso se estrutura a partir de uma posição determinada, as pessoas falam sempre de algum lugar. As mesmas falas, em situações distintas, possuem significados diferentes [...] Por isso torna-se importante compreender o momento em que elas foram engendradas e a que necessidades procuravam responder (ORTIZ, 1985, p. 67).

A palavra outra, de um sujeito outro, indispensável na constituição do eu, se trata de uma palavra concreta, de um outro sólido e não algo idealizado teoreticamente com caráter abstrato; se trata de uma relação sujeito-sujeito e é essa relação que permite o encontro de palavras de sujeitos produtores de atos responsáveis que armam o universo cultural. A palavra materializada pelos sujeitos como discurso marca os seus lugares sociais e posicionamentos (PONZIO, 2010). O ser responsavelmente ativo, na integração do próprio lugar no mundo, "é também apreensão pelo outro, que me obriga responsavelmente; somente do lugar único próprio é possível fazer doações, a responsabilidade da ação é acima de tudo responsabilidade por outros e a minha unicidade é a não delegabilidade" (PONZIO, 2013, p. 249).

Nessa esteira de pensamento, para se compreender a cultura que se encarna por meio dos atos humanos, a cultura como fenômeno armado da imanência da vida e não como produto objetificado, torna-se necessário compreender a produção discursiva do homem, torna-se necessário olhar para seus atos responsáveis que também se dão pela palavra, pelos seus encontros e reverberações, que por seu turno é o fenômeno ideológico por excelência. "A realidade de toda da palavra é absorvida por sua função de signo. A palavra não comporta nada que não esteja ligado a essa função, nada que não tenha sido gerado por ela" (BAKHTIN; VOLOCHÍNOV, 2009, p. 36).

Ela é o caminho para se atingir o humano, posto que seja o instrumento de humanização do ser, e se compreendemos o homem, compreendemos sua cultura. É pela palavra que conseguimos alcançar os modos de agir dos sujeitos, é por ela que se evidencia a beleza do diálogo continuado dos atos humanos. É a partir do mais denso penetrar no império dos signos, na palavra constituída na vida, que se pode compreender os fenômenos que compõem a cultura se distanciando de uma ordem natural, posto que a arquitetônica da vida de cada sujeito se conforma por um suceder de atos concretos, singulares, únicos, distintos uns dos outros, mas que encerram subsídios relacionais com outros atos e por isso dão feitio ao processo dialógico da interação humana pela linguagem que constitui suas esferas culturais.

É pela palavra que a linguagem conjetura o contexto social, aquilo que se encontra alhures dos enunciados; ela abrange mais longe e mais espaçosamente o que se localiza na feição propriamente material da enunciação, traz consigo as valorações constituídas nas interações entre os sujeitos, isto é, traz as vozes que armam a circunstância extraverbal dos discursos. "A palavra na vida, com 
toda evidência, não se centra em si mesma. Surge da situação extraverbal da vida e conserva com ela o vínculo mais estreito. E mais, a vida completa diretamente a palavra, que não pode ser separada da vida sem que perca seu sentido" (VOLOCHÍNOV, 2014, p. 77), por esse motivo ela é pessoal e social ao mesmo tempo, é um aparato ideológico e engenharia da transformação social e concretização de juízos axiológicos e valorativos que "se referem à totalidade, na qual a palavra diretamente entra em contato com o acontecimento da vida e se funde com ele em uma unidade indissolúvel. A palavra tomada isoladamente, como fenômeno puramente linguístico, não pode ser verdadeira, nem falsa, nem atrevida, nem tímida. [...] assim, a palavra resolve a situação, ao proporcionar uma espécie de resumo valorativo" (VOLOCHÍNOV, 2014, p. 77-9).

A palavra funciona como a interposição pela qual os sujeitos se apreciam e se distinguem culturalmente. A palavra é cultural como produto das mãos humanas, é materialmente tecida por uma vastidão de traços ideológicos e por isso revela as relações transitórias no domínio social. "Logo, o social em sua base é plenamente objetivo: trata-se antes de tudo de uma unidade material do mundo, que forma parte do horizonte dos falantes e da unidade das condições reais da vida, que geram a comunidade das valorações" (VOLOCHÍNOV, 2014, p. 80).

Tanto é verdade que a palavra penetra literalmente em todas as relações entre indivíduos, nas relações de colaboração, nas de base ideológica, nos encontros fortuitos da vida cotidiana, nas relações de caráter político, etc. É, portanto, claro que a palavra será sempre o indicador mais sensível de todas as transformações sociais, mesmo daquelas que apenas despontam, que ainda não tomaram forma, que ainda não abriram caminho para sistemas ideológicos estruturados e bem formados. A palavra constitui o meio no qual se produzem lentas acumulações quantitativas de mudanças que ainda não tiveram tempo de adquirir uma nova qualidade ideológica, que ainda não tiveram tempo de engendrar uma forma ideológica nova e acabada. A palavra é capaz de registrar as fases transitórias mais íntimas, mais efêmeras das mudanças sociais (BAKHTIN; VOLOCHÍNOV, 2009, p. 42).

O penetrar no mundo dos signos só é possível pela interação verbal, pela palavra, e tão unicamente por ela é que o ser humano ergue sua história ao mesmo tempo em que é erguido por ela dentro de uma intimidade necessária; de uma simbiose, de uma interação sujeito-sujeito e sujeito-mundo pela linguagem. Esse acontecimento social que cognominamos linguagem abriga uma relação mútua de constituição do eu e do outro, portanto, dos sujeitos, e é edificada sobre determinações ideológicas dadas, o que faz com que os sujeitos não se constituam apenas pela ação discursiva, mas por todas as atividades humanas que oferecem espaços de encontros de constituição da subjetividade pela composição dos sentidos, isto é, pela cultura. Isso quer dizer que os processos de disposição da cultura são determinados por essa dialogicidade que se ajeita na construção da linguagem, nos mais variados gêneros do discurso que os sujeitos utilizam para se comunicar, vivenciar e concretizar seus atos éticos.

Ponzio (2010a, p. 37) compreende que a "dialogicidade não é característica de um certo tipo de palavra, mas é a dimensão constitutiva de qualquer ato de palavra, de discurso. Cada palavra própria se realiza em uma ação dialógica e recupera os sentidos da palavra alheia". Assim, o ato de enunciação sempre reitera 
um intercâmbio do eu com o outro pela palavra, que os ligam dialogicamente e produzem respostas, réplicas e colocam em ação a plurivocalidade que inventa a cultura.

Bakhtin, em todos os estudos que compõem sua filosofia da linguagem, sobretudo os relacionados à cultura, teve o desejo de auscultar o ato dialógico em seu nascedouro, a vida de dentro dela própria, da imanência da sua axiologia, "pois a vida é dialógica por natureza e viver significa participar do diálogo: interrogar, ouvir, responder, concordar etc. Nesse diálogo o homem participa por inteiro e com toda a vida: com os olhos, os lábios, as mãos, a alma, o espírito, todo o corpo, os atos" (GEGE, 2009, p. 29).

É nesse universo dos jogos éticos, dos conjuntos de valores formados paulatinamente que são determinadas as interações e relações humanas que configuram o orbe da cultura e que Bakhtin considera ser o nascedouro dos discursos, das ideologias, dos embates sociais, do ato responsável, que nos fazem compreender o próprio homem. Para nós, estudiosos da linguagem, é pela língua em suas mais variadas potencialidades semióticas, na sua concretude e na sua vivencialidade fortuita que temos a possibilidade de compreender os processos da comunicação verbal, pelos quais podemos ouvir a voz da alteridade, perceber a cor e a entoação daquilo que se caracteriza em oposição a uma identidade monológica e acabada do eu.

Para Bakhtin a língua é basicamente a manifestação de uma visão de mundo e tem uma realização efetiva no discurso. O discurso é uma enunciação que torna possível considerar a performance da voz que o enuncia e o contexto social em que é enunciado. Ele entende, desse modo, a impossibilidade de analisar o discurso fora do ambiente em que é realizado e que o atribui à palavra seu matiz ideológico, vale dizer dialógico (MACHADO, 1990, p. 138).

É pela língua enquanto visão de mundo, materializada em palavras outras que podemos compreender a cultura como fenômeno simbólico, discursivo e dialógico que diz respeito à própria realidade, à diversidade humana, à manifestação do pensamento do homem e sua valoração axiológica do mundo, os modos de interação dos indivíduos de um determinado grupo, os meios de ação em contextos singulares, a vida do homem na imensidão do universo dos grupos socialmente organizados. A cultura é essa organização, "essas formas características de energia humana que podem ser descobertas como reveladoras de si mesmas - dentro de identidades e correspondências inesperadas, assim como em descontinuidades de tipos inesperados dentro ou subjacente a todas as demais práticas sociais" (HALL, 2003, p. 145).

Envolver os fenômenos da cultura pela palavra outra, pela palavra inacabada que reitera a alteridade, pela palavra que abre o coração do homem e faz o mundo ser cantado, materializado ideologicamente na entoação dos seus lábios, significa compreender como as ações humanas ganham significações nos gestos que desvelam suas almas, nos atos que pronunciam os vislumbres das suas cobiças internas, das suas valorações sociais, das suas formas de relação com o outro, dos modos de dar feição à sociabilidade humana, cujos "pensamentos, opiniões, visões de mundo, consciência se constituem e se elaboram a partir de relações dialógicas 
e valorativas com outros sujeitos, opiniões e dizeres. A alteridade é fundamento da identidade" (GEGE, 2009, p. 13).

Afinal, é compreender o mundo da cultura evidenciado pela palavra sedutora, ideológica, dialógica, que preserva em si segredos impenetráveis que não satisfazem as probabilidades acabadas que residem no fantasioso universo dos sentidos e, por isso, se faz misteriosa ao representar também o lado inefável do mundo constituído pelos sujeitos nas suas unicidades.

\title{
6. A CULTURA POPULAR COMPREENDIDA POR BAKHTIN PELA PALAVRA DE RABELAIS
}

Nos estudos de Bakhtin e do Círculo, a principal cobiça era abarcar a vida de dentro dela própria, como lugar de nascedouro das ideologias, não pelos seus atos únicos, impossíveis de serem aprendidos na sua ação ética, mas pela sua representação na esfera estética por meio da palavra. Para Bakhtin (2008), o que interessava ao auscultar a cultura cômica popular, encarnada na obra de Rabelais, era o jogo, a luta entre essas duas culturas se dando nos mesmos espaços. Assim, ele buscava compreender por meio da palavra do francês

\begin{abstract}
a grande linha principal da luta de duas culturas, a cultura popular e a cultura oficial medieval. Observamos várias vezes que essa grande linha se ligava organicamente aos ecos da atualidade, aos acontecimentos grandes e pequenos dos anos, meses e mesmo dias, em que Rabelais escrevia as diferentes partes do seu livro. Pode-se dizer que toda a obra, do começo ao fim, saiu do próprio centro da vida da época, na qual o autor era um participante ativo ou uma testemunha interessada (BAKHTIN, 2008, p. 385).
\end{abstract}

No trabalho do filósofo são evidenciadas as contradições, mas não de modo esquemático em que o popular ostenta uma patente hierárquica arraigada de poderes que debelem a cultura oficial e seus constituintes e nem de uma maneira acastelada como um meio de uso particular de um determinado grupo ou classe social. Ele reconhece que "nesse espetáculo real sem palco, onde se dava os festejos populares, é impossível traçar uma fronteira nítida entre a realidade e o símbolo" (BAKHTIN, 2008, p. 213). Essa falta de palco é qualidade de todas as configurações da festa popular. Ela libera a "verdade utópica que se representa na própria vida. Por um breve período, ela se torna até certo ponto uma força real que pode servir para punir inimigos hereditários da verdade" (BAKHTIN, 2008, p. 231). No entanto, há aí uma diferença de classes, há "uma fronteira interna, clara, que delimita os dois aspectos: mesmo existindo lado a lado, eles não se confundem, não se misturam (BAKHTIN, 2008, p. 83).

Nelas, Bakhtin procura compreender os aspectos populares da cultura do povo, ao abranger os mecanismos que arquitetam as manifestações cômicas dos festejos e nas interações da praça pública na Idade Média por meio da palavra do escritor francês, por considerar que "sua obra constitui uma enciclopédia da cultura popular" (BAKHTIN, 2008, 50). Deste modo, se atenta às "1. Formas dos ritos e espetáculos (festejos carnavalescos, obras cômicas representadas nas praças 
públicas e etc.); 2. Obras cômicas verbais (inclusive as paródicas) de diversas naturezas: orais e escritas, em latim ou em língua vulgar; 3. Diversas formas e gêneros do vocabulário familiar e grosseiro (insultos, juramentos, blasões populares, etc.)" (BAKHTIN, 2008, p. 4).

$\mathrm{Na}$ cultura popular cômica da Idade Média e do Renascimento, Bakhtin (2008) vai buscar o avesso da ordem social da concepção dominante do mundo, que se evidencia na palavra de Rabelais. Nele,

o pensamento e a palavra procuram uma realidade nova, para além do horizonte aparente da concepção dominante. E por vezes, palavras e pensamentos viravam-se de propósito, para ver o que se encontrava verdadeiramente por trás deles, qual era seu avesso. Procuravam a posição a partir da qual pudessem ver a outra margem das formas de pensamento e dos julgamentos dominantes, a partir da qual pudessem lançar olhares novos sobre o mundo (BAKHTIN, 2008, p. 237)

Sua concepção estética não aprecia a negação abstrata e imaculada, nem a afirmação monológica, posto que se pauta nas interações vivas, dinâmicas na praça pública, nas imagens ambivalentes da cultura popular destituída de qualquer inocência, recheada de riso e da audácia cômica que não necessita da condescendência oficial.

Ele tomou de fontes orais um número considerável dos elementos de sua linguagem: trata-se de palavras virgens que, saídas pela primeira vez das profundezas da vida popular, da língua falada, entraram para o sistema da linguagem escrita e impressa. Os léxicos de quase todos os ramos da ciência saíram, na sua parte, da linguagem oral e pela primeira vez participaram de um contexto livresco, de um pensamento livresco sistemático, de uma entoação escrita livresca, de uma construção sintática escrita e livresca (BAKHTIN, 2008, p. 402).

Para Ponzio (2008, p. 170), Bakhtin dirigia "a atenção especial ao riso ritualista e à festa popular, encontrando neles a chave para explicar imagens específicas, motivos e gêneros de produção artística da cultura popular que penetram na literatura oficial, como no caso de Rabelais".

No centro desse universo popular, festivo, risível,

assiste-se a uma liberação consequente da palavra e do gesto dos tons penosamente sérios da prece, da lamentação, da humilhação, da piedade e daquelas, ameaçadores, da intimidação, da ameaça, da interdição. Todas as expressões oficiais que os homens da Idade Média empregavam, estavam exclusivamente impregnadas por esses tons, estavam envenenadas por eles, pois a cultura oficial ignorava a seriedade isenta de medo, livre e lúcida (BAKHTIN, 2008, p. 334).

Portanto, os estudos da composição de Rabelais configuram grande autoridade para o entendimento da cultura por meio da palavra, sobretudo da cultura popular como o lugar do destronamento, do embate entre o pequeno e o grande em pé de igualdade. Para Bakhtin (2008), Rabelais se tornou um exímio porta-voz da cultura cômica popular pelo motivo de ter por escora as práticas cotidianas que acentuam a civilização humana, por ser um presunçoso apreciador das festividades, das relações estabelecidas na praça pública, do grotesco que constituía os personagens do carnaval e que serviam de nascedouro do qual provinha a riqueza que recheia a sua obra, pela qual inventa um mundo infinito das formas e manifestações do 
riso, contrapondo-se à oficialidade, à entoação sisuda, monástica e ortodoxa do seu tempo.

No íntimo de sua dessemelhança tais feitios e eventos - as festas públicas carnavalescas, os ritos e cultos cômicos especiais, os bufões e tolos, gigantes, anões e monstros, palhaços de diversos estilos e categorias, etc. - constituem artefatos da cultura popular, principalmente, da cultura carnavalesca, na qual todos esses rituais e espetáculos instituídos pelo caráter cômico ofereciam uma visão de mundo, dos sujeitos e das suas relações inteiramente distintas, deliberadamente não-oficial, exterior à Igreja e ao Estado; em que parecia ser construído ao lado do mundo oficial um segundo mundo e uma segunda vida, uma espécie de dicotomia que se fundamentava nas práticas do cotidiano (BAKHTIN, 2008).

Por intervenção do riso do povo e da desonra dos símbolos ajuizados, o pavor absorto do incógnito fazia-se carne, convertido em assombro grotesco, feito para fazer rir e para ser dominado (GARDINER, 2010). Em Rabelais, o riso aparece como regeneração e subversão desse pensamento unilateral. Daí Bakhtin (2008) o reconhecer como o mais democrático dos modernos mestres da literatura cuja sua basilar qualidade é justamente a de estar, mais que alguns outros autores, cuidadoso e congregado às fontes populares que instauravam a unidade da cultura de seu tempo, essas que encarnam pelo riso a arquitetônica do conjunto de imagens grotescas no interior de seus escritos. Para ele, esse riso é, antes de mais nada, um riso festivo, um riso carregado de imagens grotescas.

Tais imagens são prenhes desse riso e, por isso, são verdadeiras alegorias que formam o princípio material e corporal, que é o da festa, do banquete, da alegria, que subsiste consideravelmente na literatura e na arte do Renascimento. Em Rabelais, esse ato evidencia o realismo grotesco de que fala Bakhtin (2008, p. 17), por meio do "rebaixamento, isto é, a transferência ao plano material e corporal, o da terra e do corpo na sua indissolúvel unidade, de tudo que é elevado, espiritual, ideal e abstrato".

São essas imagens que configuram as manifestações da cultura popular na Idade Média e que reconstroem um riso que resiste e escapole aos amoldamentos instaurados pelos cânones e regras da arte literária em voga. Um riso coletivo, um riso popular, um riso que se opunha a tudo o que se configurava em impostura, a tudo o que era cominado, ajuizado. Esse riso que está por detrás do sério e que se apresenta na obra de Rabelais evidencia um dos principais atributos que Ponzio (2008, p. 180) considera ter a cultura popular: "a relação entre ideologia oficial e ideologia não oficial, que pela comicidade popular põe em discussão as formas da cultura dominante".

Vê-se, pois, que a porta de entrada escolhida por Bakhtin para estudar a cultura popular na Idade Média e no Renascimento fora a palavra materializada na obra de Rabelais, tendo como fio condutor dos sentidos procurados o riso, por esse evidenciar os lugares em que aconteciam os jogos de classes, que congregava na mesma atmosfera a praça e o palácio, corroborando uma a ordem estética da cultura popular, por esse constituir os encontros de palavras de onde emergem os sentidos nas esferas ética e estética. E esse encontro se dá de forma dialógica com comandos dos dois lados e torna a esfera da cultura o orbe distintivo do homem, cumulativa, transmissível 
e dinâmica, tradicional e transformadora, ao se materializar por meio de ações éticas e simbólicas que configuram um sistema de sentidos mediante o qual uma sociedade é refletida, reproduzida e experimentada na sua vivencialidade intensa.

\section{7. (IN)CONCLUSÕES, SEMPRE INACABADAS}

Compreender os eventos e as manifestações que compõem o mundo da cultura é um experimento de desvendar os contornos da disposição que molda o terreno emaranhado das relações humanas que acontecem no contexto imediato da vida. Esse universo se torna o lugar do diálogo ininterrupto, o lugar de vivência da palavra popular de dupla tonalidade que Bakhtin encontra em Rabelais, posto que ela "não se separe jamais nem do todo nem do devir; a palavra de dupla tonalidade não tenta entravar a roda que corre e gira, a fim de nela encontrar e delimitar o alto e o baixo, frente e trás; pelo contrário, fixa sua permutação e fusão contínuas" (BAKHTIN, 2008, p. 380).

Esse universo dinâmico de constituição da palavra - a vida - inscreve um conjunto de demandas, de embates, de transgressões, de hegemonias, de tensões ideológicas que pelejam e conduzem as disputas de classes e dos diversos grupos socialmente organizados, que procuram fixar seus pertencimentos simbólicos no universo cultural, por meio das infinitas atividades relativamente estáveis que os circunscrevem materializam a arquitetônica da cultura.

Nesse sentido, a cultura se infantaria por um rico conjunto material e sígnico essencial aos estudos da linguagem, como meio de questionar, desmistificar, desconstruir e refletir as verdades intransigentes, as (in)compreensões consolidadas a respeito do mundo cultural. Nessa vereda, envolvemos a cultura como objeto de estudo da filosofia da linguagem e na perspectiva bakhtiniana; ela se liga diretamente ao cotidiano da esfera ética, porque nela coloca-se "a vida no centro e defende-a e promove-a contra todos os mecanismos de diminuição, de estancamento e de morte" (BOFF, 2000, p. 13).

Ter a vida como eixo significa abrir-se ao diferente, dar espaço à alteridade. Caso contrário, fechar-se ao outro é decretar a morte dos sentidos; é quebrar a corrente comunicativa que deve ser ininterrupta; é expulsar o outro de dentro do $\mathrm{Eu}$ e do mundo, expulsando-se com ele; é assujeitar-se. O assujeitamento só pode se dar pela expulsão do outro, quando o social não mais determina o eu. Isso é a morte.

Portanto, compreender o dinamismo da cultura que torna a vida rica, espontânea e digna de ser contemplada, é também compreender os sujeitos que, do mesmo modo, são dinâmicos, intensos, interacionais e inacabados com subjetividades dialógicas em construção social. Na tentativa de compreender a cultura contemporânea como o miolo da energização de novos valores éticos, de novos atos estéticos, enfatizamos a alteridade como o artifício constitutivo da dilatação das relações entre o homem e seus grupos sociais, o homem e a natureza, o homem e Deus, o que revela a interação de sujeitos históricos e ideológicos que adquirem sentido, somente, na relação com os outros que lhe dão acabamento 
provisório. "É para essa provisoriedade que Bakhtin nos chama a atenção. E mais além, diz-nos que os sentidos elaborados jamais se constituíram fora das relações com os outros, fora do diálogo, que existiu, que existe e que permanecerá quando nos formos e nem mais lembrança houver" (GERALDI, 2014, p. 8).

Destarte, a cultura e a vida se juntam de modo ininterrupto entrelaçando as esferas ética e estética na materialização da linguagem empregada na comunicação humana por meio de enunciados que revelam o agir responsável dos sujeitos na concretude do existir pela palavra dialógica e pela abertura da alteridade em constituição das identidades. Portanto, compreender a cultura, os sujeitos que a arquitetam e seus atos responsáveis em interação com a alteridade só é possível pela palavra e seus encontros prenhes de sentidos.

\section{REFERÊNCIAS}

BAKHTIN, M. A cultura popular na Idade Média e no Renascimento: o contexto de François Rabelais. Tradução Yara Frateschi. São Paulo: Hucitec/Brasília: Ed. UnB, 2008. 420 p.

BAKHTIN, M. Estética da criação verbal. São Paulo: Martins Fontes, 2003.

BAKHTIN, M. Para uma filosofia do ato responsável. São Carlos: Pedro \& João, 2010.

BAKHTIN, M. Questões de literatura e de estética: a teoria do romance. Aurora FornoniBernadini, et al (Trad.). 6 ed. São Paulo: Hucitec, 2010a. (Linguagem e Cultura; v.18).

BAKHTIN, M.; VOLOCHÍNOV, V. Marxismo e filosofia da linguagem: problemas fundamentais do método sociológico na ciência da linguagem. 13 ed. São Paulo: Hucitec, 2009.

BOFF, Leonardo. Ética da Vida. $2^{\mathrm{a}}$ ed. Brasília: Letraviva, 2000.

GARDINER, M. O carnaval de Bakhtin: a utopia como crítica. p. 211-255. In: RIBEIRO, A. P. G.; SACRAMENTO, I (org). Mikhail Bakhtin: linguagem, cultura e mídia. São Carlos: Pedro e João Editores, 2010.

GERALDI, J. W. Ancoragens: estudos bakhtinianos. São Carlos: Pedro \& João Editores, 2010.

GERALDI, J. W. Heterocientificidade nos estudos linguísticos. In: GEGE. Palavras e contrapalavras: enfrentando questões da metodologia bakhtiniana. São Carlos: Pedro \& João Editores, 2012. p. 19-39.

GERALDI, J. W. O mundo não nos é dado, mas construído. In: VOLOCHÍNOV, V. N. (do Círculo). A construção da enunciação e outros ensaios. Org., Trad. e Notas João Wanderley Geraldi. São Carlos: Pedro \& João Editores, 2014. p. 7-27.

GRUPO DE ESTUDOS DOS GÊNEROS DO DISCURSO - GEGE. Palavras e contrapalavras: glossariando conceitos, categorias e noções de Bakhtin. São Carlos: Pedro e João Editores, 2009.

HALL, S. A centralidade da cultura: notas sobre as revoluções de nosso tempo. Educação \& Realidade, v. 22, n. 2, p. 15-46, 1997. 
HALL, S. Notas sobre a desconstrução do popular. In: culturais. Belo Horizonte: Editora UFMG, 2003, p. 231-247.

LARAIA, R. B. Cultura: um conceito antropológico. 14 ed. Rio de Janeiro: Zahar, 2001.

MACHADO, I. A teoria do romance e a análise estético-cultural de M. Bakhtin. São Paulo, Revista USP, mar. 1990.

MIOTELLO, V. Ideologia. p. 167-176. In: BRAIT, B. (org). Bakhtin: conceitos-chave. São Paulo: Contexto, 2010.4 ed. 3 reimpressão.

MIOTELLO, V. Os discursos hegemônicos são turbulentos. In: Grupo de Estudos dos Gêneros do Discurso. Quimera e a peculiar atividade de formalizar a mistura do nosso café com o revigorante chá de Bakhtin. São Carlos: GEGE, 2004. p.63-74.

MIOTELlo, V.; MOURA, M. I. Alargando os limites da identidade (apresentação). In: GEGE. $A$ escuta como lugar do diálogo: alargando os limites da identidade. São Carlos: Pedro \& João Editores, 2012.

ORTIZ, R. Cultura brasileira e identidade nacional. São Paulo: [s.n.], 1985. 148 p.

PETRILLI, S. Em outro lugar e de outro modo: filosofia da linguagem, crítica literária e teoria da tradução em, em torno e a partir de Bakhtin. São Carlos: Pedro \& João, 2013.

PONZIO, A. A concepção bakhtiniana do ato como dar um passo. In: BAKHTIN, M. Para uma filosofia do ato responsável. São Carlos: Pedro \& João Editores, 2010. p. 9-40.

PONZIO, A. Procurando uma palavra outra. São Carlos: Pedro \& João Editores, 2010a.

PONZIO, A. A revolução bakhtiniana: o pensamento de Bakhtin e a ideologia contemporânea. Coordenação de tradução Valdemir Miotello. São Paulo: Contexto, 2008.

PONZIO, A. No círculo com Mikhail Bakhtin. Tradução aos cuidados de Valdemir Miotello, Hélio M. Pajeú, Carlos A. Turati e Daniela M. Mondardo. São Carlos: Pedro \& João, 2013.

SOBRAL, A. Do dialogismo ao gênero: as bases do pensamento do círculo de Bakhtin. São Paulo: Mercado das Letras, 2009. (Ideias sobre linguagem).

SOUZA, G. T. A construção da metalingüistica (fragmentos de uma ciência da linguagem na obra de Bakhtin e seu círculo). 2002. 167 f. Tese (Doutorado em Letras) - Faculdade de Filosofia, Letras e Ciências Humanas, Universidade de São Paulo, São Paulo, 2002.

SUASSUNA, A. Iniciação à estética. Recife: Ed. Universitária, 1979.

THOMPSON, J. B. Ideologia e cultura moderna: teoria social critica na era dos meios de comunicacao de massa. 6 ed. Petrópolis: Vozes, 2002.

VOLOCHÍNOV, V. N. (do Círculo). A construção da enunciação e outros ensaios. Org., Trad. e Notas João Wanderley Geraldi. São Carlos: Pedro \& João Editores, 2014. 